\title{
Analysis of Factors to Influence Yarn Dynamical Mechanical Property
}

\author{
Qian Wang, Jiankun Wang \& Ling Cheng \\ School of Textiles \\ Tianjin Polytechnic University \\ Tianjin 300160, China \\ E-mail: yybbxj1@126.com
}

\begin{abstract}
The mechanical property of yarn influences the mechanical property and endurance of textiles to large extents. At present, the research and evaluation of yarn mechanical property mainly refer to some static testing indexes such as breaking strength and tensile strength at break of yarn mechanical property. However, these indexes can not comprehensively reflect the mechanical property of yarn in the spinning and using process. In this article, we adopt the CTT yarn property testing instrument made by US Lawson Company to test the dynamic strength of yarn, and analyze factors to influence the yarn dynamic strength, and more objectively evaluate the mechanical property of yarn.
\end{abstract}

Keywords: Mechanical property, Dynamic strength, CTT, Influencing factors

\section{Introduction}

The testing indexes of yarn mechanical property mainly include tensile breaking strength, relative strength, breaking elongation and tensile distortion. In these indexes, the yarn strength is the most important index to influence yarn property and reflect the interior quality of yarn, and it is the necessary condition to possess machining property and final purpose, and the technical parameter involved in various working procedures such as spinning and knitting.

The modern testing instrument of single yarn has been very advanced, and it can display breaking load, breaking elongation, breaking power and their variation coefficients. In the spinning, the information can offer directions of relative properties among yarns. However, the information can not completely predict the operation status of yarn, because it is not enough to only consider the static mechanical indexes of yarn. In the subsequent machining process, yarn will continually suffer tension and friction and always be in the dynamic status, but not in the static status. Therefore, it is more meaningful to research the mechanical property of yarn under the dynamic mechanical condition. The CTT yarn property testing instrument made by US Lawson Company can realize the strength testing of yarn under the dynamic condition.

\section{Experiment instruments}

The experiment instruments include CTT yarn property testing instrument and Y331A Twister.

\subsection{Brief introduction of CTT}

CTT (Constant Tension Transport) (seen in Figure 1) is the yarn property testing instrument made by US Lawson Company. The meaning of CTT is that under the draught of constant tension $(1.96-735 \mathrm{cN})$ exactly selected, the yarn can be transported by the selected speed, which is an important character. The instrument is the international advanced multi-function yarn property analysis and testing system, and it is composed by many testing modules such as EIB (electric imitation blackboard), YAS (yarn quality analysis), DET (dynamic extension testing), LGT (yarn down quality testing), DTT (dynamic friction coefficient testing) and YAT (abrasion resistant testing). It can not only implement yarn comprehensive property testing analysis and research the influences of physical mechanical property, structure and apparent characters of different yarns to performance of fabrics, but implement quality evaluation to the yarn according to the international standard. In this article, we mainly use the DET module to test the dynamic strength of yarn and analyze the factors influencing the dynamical strength of yarn.

\subsection{Testing method of CTT}

The basic parts of CTT are composed by input roller, output roller and tension sensors. The output roller runs by the constant speed $(20-360 \mathrm{~m} / \mathrm{min})$, and the speed of input roller is maintained on certain value with the set tension. The speed difference between input roller and output roller makes the tension endured by yarn in the operation process keep on the set value. When the dynamic testing is implemented, we can gradually increase the set tension to observe the operation of yarn, and once the breaking happens, so the set tension value here represents the dynamic breaking strength of the testing yarn, and the dynamic breaking elongation ratio of measured yarn can be computed according to the speed 
difference between input roller and output roller, and though this method, we can also establish the relationship between yarn dynamic tension and yarn elongation. Otherwise, the average breaking strength and its variation coefficient of yarn and the average of dynamic running tension and its variation coefficient which is also very important to analyze the running status of yarn can be computed according to the testing tension value.

\section{The experiments and analysis of factors to influence dynamic strength of yarn}

The experiment environment: all experiments are implemented in the lab with the temperature of $25^{\circ} \mathrm{C}$ and the relative humidity of $65 \%$.

The main factors to influence the yarn breaking strength include fiber length, fiber intention, fiber fineness and yarn twist. We will compare and analyze the factors to influence the yarn dynamic strength from flowing aspects.

\subsection{Influence of yarn twist to yarn dynamic strength (experiment 1)}

\subsubsection{Experiment}

(1) Sample: 20 pipes of $40^{\mathrm{s}}$ pure cotton yarn.

(2) Testing: a. the twist. b. the dynamic strength under the running speeds of $100 \mathrm{~m} / \mathrm{min}, 200 \mathrm{~m} / \mathrm{min}$ and $360 \mathrm{~m} / \mathrm{min}$, and the influences of twist to yarn dynamic strength.

\subsubsection{Testing result and analysis}

The testing results are seen in Table 1. The data in Table 1 can be described as following curves seen in Figure 2, Figure 3 and Figure 4.

From Figure 2, we can see that (1) the dynamic strength of yarn increases with the increase of twist, and when the twist achieves the certain value, i.e. 96.5 twists $/ 10 \mathrm{~cm}$, the dynamic strength of yarn begins to reduce instead with the increase of twist, (2) the curve is smooth, and when the yarn running speed, $\mathrm{V}=100 \mathrm{~m} / \mathrm{min}$, the change of its dynamic strength is stable with the change of twist, and there is not biggish fluctuation.

From Figure 3, we can see that (1) the dynamic strength of yarn increases with the increase of twist, and when the twist achieves the certain value, i.e. 96.5 twists $/ 10 \mathrm{~cm}$, the dynamic strength of yarn begins to reduce instead with the increase of twist, which is same with the above figure, (2) the inflexion appears in the curve, which indicates that the change of yarn dynamic strength has certain fluctuation and it is not very stable.

From Figure 4, we can see that (1) the dynamic strength of yarn increases with the increase of twist, and when the twist achieves the certain value, the dynamic strength begin to reduce whereat increase, and when the twist achieves 98.0 twists $/ 10 \mathrm{~cm}$, the dynamic strength reduces, (2) the fluctuation extent of the curve is large, which indicates that when the running speed $\mathrm{V}=360 \mathrm{~m} / \mathrm{min}$, the change relationship of yarn dynamic strength is complex and unstable with the change of twist.

The reason is that the breaking always happens in the feeblest section under the pull for a length of yarn. To the short fiber yarn, there are two situations that it breaks because of the outside pull force, and one is that the breaking of fiber makes the yarn break, and the other is the surge among fibers makes the yarn break. The influence of twisting function to the yarn strength is decided by the integration of advantage factors and disadvantage factors. When the twist is small, the twisting function is mainly represented to improve the unevenness ratio of yarn strength and reduce the surge fiber amount of yarn breaking, so the yarn strength increases with the increase of twist. When the twist achieves certain value, the twisting function is mainly represented to increase the pre-stress of fiber in yarn and reduce the axes component force of fiber intension, so the yarn strength gradually reduces with the increase of twist. Three above curves all embody this rule, and with the increase of twist, the twist-dynamic strength curve of yarn fluctuates largely (Yao, 1993).

\subsection{Influence of yarn running speed to yarn dynamic strength (experiment 2)}

\subsubsection{Experiment}

(1) Sample: 20 pipes of $40^{\mathrm{s}}$ pure cotton yarn, and their breaking strengths are close.

(2) Testing: change different running speeds, and respectively test the dynamic strengths of yarn when $\mathrm{V}=100 \mathrm{~m} / \mathrm{min}$, $\mathrm{V}=200 \mathrm{~m} / \mathrm{min}$ and $\mathrm{V}=360 \mathrm{~m} / \mathrm{min}$, and analyze the influences of running speeds to dynamic strengths.

\subsubsection{Testing result and analysis}

The testing results are seen in Table 2. The data in Table 2 can be described as following curves seen in Figure 5, Figure 6 and Figure 7.

From Figure 5, we can see that (1) the values of yarn dynamic strength are mainly focused in $113-123 \mathrm{cN}$, (2) the yarn dynamic strength presents normal school, and the rule closes to the static single yarn strength.

From Figure 6, we can see that (1) the values of yarn dynamic strength are mainly focused in $107-121 \mathrm{cN}$, (2) the yarn dynamic strength frequently appears in the range of $99-103 \mathrm{cN}$, which indicates the strength is relative low, (3) when the 
running speed increases, the yarn dynamic strength goes to reduce.

From Figure 7, we can see that (1) the values of yarn dynamic strength are mainly focused in $107-121 \mathrm{cN}$, (2) the yarn dynamic strength frequently appears in the range of $99-103 \mathrm{cN}$, which indicates the strength is relative low, (3) when the running speed increases, the yarn dynamic strength goes to reduce.

From Figure 8, we can see that (1) when $\mathrm{V}=100 \mathrm{~m} / \mathrm{min}$ and $\mathrm{V}=200 \mathrm{~m} / \mathrm{min}$, the fluctuation extension of curve is small, and when $\mathrm{V}=360 \mathrm{~m} / \mathrm{min}$, the fluctuation extension of curve is large, which indicates that when the running speed is lower, the yarn dynamic strength is relative stable, and when the running speed is higher, the yarn dynamic tension changes largely, and the tension is difficult to be controlled, (2) the curve of $\mathrm{V}=100 \mathrm{~m} / \mathrm{min}$ goes up and the curve of $\mathrm{V}=360 \mathrm{~m} / \mathrm{min}$ goes down, which indicates that under usual situation, the running speed of yarn is higher, its dynamic strength is smaller. The results also tell us that in the subsequent process, we can not make yarn exceed its dynamic tension, or else the breaking will happen, and the running speed of yarn should be controlled better, and the speed should not be higher to avoid the large extent fluctuation of yarn tension.

From Table 3, we can see that (1) the $\Delta$ ( $\Delta=$ single yarn strength - dynamic strength) of the No. 8 yarn is maximal, and its single yarn strength and dynamic strength is very large, which indicates the twist influences the strength of yarn whether in static condition or in dynamic condition to some extents, (2) the $\Delta$ of the No. 9 yarn is minimum, and though its twist is very high, but its strength is very low, which indicates the twist is not the only factor to decide the yarn strength, and the yarn dynamic strength is influenced by other factors.

\subsection{Influence of average fiber length to yarn dynamic strength (experiment 3 )}

\subsubsection{Experiment}

(1) Sample: the cotton yarns with the fineness of about 20tex, 1\# yarn is the upland cotton with the length of $29 \mathrm{~mm}$, and $2 \#$ yarn is the long-staple cotton with the length of $37 \mathrm{~mm}$.

(2) Testing: respectively test the breaking strength and the dynamic strength of yarn, and analyze the influence of the average fiber length to the dynamic strength of yarn.

\subsubsection{Testing result and analysis}

The testing results are seen in Table 4. From Table 4, we can see that (1) the average length of cotton fiber is longer, its breaking strength and dynamic tension of yarn is higher, and the reason is that when the fiber length is long and the fineness is thin, the friction resistance among fibers in the yarn is large, and the surge hardly appears, so the yarn strength is high, (2) the difference between the breaking strength of yarn with the dynamic tension under the dynamic testing condition is large, which indicates that the amount of the weak loop in the yarn sample is plenty, and the tension of yarn has serious unevenness, and we should timely inspect and adjust it in the production process.

\subsection{Influence of fiber type to yarn dynamic strength (experiment 4)}

\subsubsection{Experiment}

(1) Sample: same $32^{\mathrm{s}}$ pure cotton yarn and $40^{\mathrm{s}}$ pure cotton yarn.

(2) Testing: test the breaking tension and dynamic tension, and analyze the influence of yarn fineness to dynamic tension.

\subsubsection{Testing result and analysis}

The testing results are seen in Table 5. From Table 5, we can see that the fineness of the yarn is higher and the breaking tension and dynamic tension is larger.

The reason is that the fiber is the unit to compose yarn, and the cross section of yarn must contain fibers with quite amount, it can possess certain tension. When the fibers are same in type but the number is different, the yarn is thinner, the fiber amount contained in the unit section is more and the strength is larger.

\subsection{Influence of yarn type to yarn dynamic strength (experiment 5)}

\subsubsection{Experiment}

(1) Sample: $32^{\mathrm{s}}$ pure cotton yarn and $32^{\mathrm{s}}$ terylene/cotton mixed yarn.

(2) Testing: test the breaking tension and dynamic tension, and analyze the difference of yarn dynamic strength of different sorts of yarn.

\subsubsection{Testing result and analysis}

The testing results are seen in Table 6. From Table 6, we can see that (1) the breaking strength CV value of the terylene/cotton mixed yarn is lower than the value of pure cotton yarn, which indicates the strength of mixed yarn is very stable, (2) the dynamic tension of the terylene/cotton mixed yarn is obviously higher than the tension of the pure cotton yarn. 
The reason is that the strength of terylene fiber is higher than the strength of pure cotton, so the mixed yarn can enhance the dynamic strength of yarn.

\section{Conclusions}

The dynamic strength of yarn is tested under the running status, so the dynamic property of yarn more really reflect the behavior of yarn in the subsequent machining process to some extent, which offers important technical parameters in the future production process for us and can better control the running status to control the yarn. Secondly, all yarns in the dynamic testing process endure the tests, and all "weak sections" in the testing yarns are tested.

In the article, we analyze the factors to influence the yarn dynamic strength, and these factors including yarn running speed, twist, fineness, fiber length, sorts and mixed ratio all influence the yarn dynamic strength to certain extent, and it is meaningful to grasp and control these influencing factors for enhancing the strength in the spinning and knitting process.

CTT yarn property testing instrument is the most advanced comprehensive property testing and analysis instrument in the world, and the development of the various function of the instrument can not only help us deeply understand and analyze the level and character of foreign advanced spinning testing technology, but offer more direct references and helps to develop new product, adopt new technology, enhance quality and work efficiency, and control the quality of yarn.

\section{References}

Hu, Wenxia. (1996). Experiment of Textile Materials. Beijing: Textile Industry Press.

Li, Ziqiang. (2008). Probability Theory and Mathematical Statistics Tutorial. Beijing: Science Press.

Wang, Hongbo. (2001). The Control and Testing of Yarn Tension. Beijing Textile Journal. No.22(5). p.17-20.

Yaomu. (1993). Science of Textile Material. Beijing: Textile Industry Press.

Table 1. The twists and dynamic tension values of yarn under different velocities

\begin{tabular}{|c|c|c|c|c|}
\hline \multirow[t]{2}{*}{ No. } & \multirow{2}{*}{$\begin{array}{c}\text { Twist } \\
\text { (twist/10cm) }\end{array}$} & \multicolumn{3}{|c|}{ Dynamic strength $(\mathrm{cN})$} \\
\hline & & $\mathrm{V}=100 \mathrm{~m} / \mathrm{min}$ & $\mathrm{V}=200 \mathrm{~m} / \mathrm{min}$ & $\mathrm{V}=360 \mathrm{~m} / \mathrm{min}$ \\
\hline $1-1$ & 97.0 & 112 & 110 & 111 \\
\hline $1-2$ & 98.2 & 120 & 117 & 125 \\
\hline $2-1$ & 94.4 & 98 & 105 & 107 \\
\hline $2-2$ & 97.4 & 114 & 125 & 94 \\
\hline $3-1$ & 93.4 & 114 & 111 & 122 \\
\hline $3-2$ & 96.5 & 133 & 130 & 112 \\
\hline $4-1$ & 95.0 & 119 & 116 & 107 \\
\hline $4-2$ & 95.3 & 118 & 117 & 123 \\
\hline $5-1$ & 95.0 & 106 & 99 & 119 \\
\hline $5-2$ & 95.3 & 108 & 113 & 110 \\
\hline $6-1$ & 98.0 & 98 & 100 & 95 \\
\hline $6-2$ & 99.2 & 113 & 103 & 95 \\
\hline $7-1$ & 94.9 & 119 & 111 & 112 \\
\hline $7-2$ & 98.3 & 113 & 118 & 115 \\
\hline $8-1$ & 102.1 & 107 & 114 & 94 \\
\hline $8-2$ & 96.5 & 114 & 103 & 108 \\
\hline $9-1$ & 99.6 & 120 & 115 & 111 \\
\hline $9-2$ & 98.8 & 110 & 120 & 117 \\
\hline $10-1$ & 95.7 & 122 & 113 & 120 \\
\hline $10-2$ & 98.8 & 112 & 114 & 95 \\
\hline
\end{tabular}


Table 2. The dynamic breaking strength values and dynamic strength values under the velocities of $100 \mathrm{~m} / \mathrm{min}$, $200 \mathrm{~m} / \mathrm{min}$ and $300 \mathrm{~m} / \mathrm{min}$

\begin{tabular}{|c|c|c|c|c|c|c|}
\hline Running velocity & \multicolumn{2}{|c|}{$\mathrm{V}=100 \mathrm{~m} / \mathrm{min}$} & \multicolumn{2}{|c|}{$\mathrm{V}=200 \mathrm{~m} / \mathrm{min}$} & \multicolumn{2}{|c|}{$\mathrm{V}=360 \mathrm{~m} / \mathrm{min}$} \\
\hline strength & $\begin{array}{l}\text { Breaking } \\
\text { strength }\end{array}$ & $\begin{array}{c}\text { Dynamic } \\
\text { strength }\end{array}$ & $\begin{array}{l}\text { Breaking } \\
\text { strength }\end{array}$ & $\begin{array}{l}\text { Dynamic } \\
\text { strength }\end{array}$ & $\begin{array}{l}\text { Breaking } \\
\text { strength }\end{array}$ & $\begin{array}{c}\text { Dynamic } \\
\text { strength }\end{array}$ \\
\hline $1-1$ & 137 & 112 & 144 & 110 & 139 & 111 \\
\hline $1-2$ & 169 & 120 & 162 & 117 & 158 & 125 \\
\hline $2-1$ & 130 & 98 & 132 & 105 & 134 & 107 \\
\hline $2-2$ & 169 & 114 & 161 & 125 & 129 & 94 \\
\hline $3-1$ & 140 & 114 & 151 & 111 & 152 & 122 \\
\hline $3-2$ & 167 & 133 & 159 & 130 & 155 & 112 \\
\hline $4-1$ & 151 & 119 & 150 & 116 & 149 & 107 \\
\hline $4-2$ & 147 & 118 & 150 & 117 & 156 & 123 \\
\hline $5-1$ & 140 & 106 & 123 & 99 & 148 & 119 \\
\hline $5-2$ & 148 & 108 & 137 & 113 & 138 & 110 \\
\hline $6-1$ & 134 & 98 & 136 & 100 & 144 & 95 \\
\hline $6-2$ & 141 & 113 & 129 & 103 & 130 & 95 \\
\hline $7-1$ & 148 & 119 & 139 & 111 & 140 & 112 \\
\hline $7-2$ & 156 & 113 & 147 & 118 & 146 & 115 \\
\hline $8-1$ & 147 & 107 & 144 & 114 & 139 & 94 \\
\hline $8-2$ & 146 & 114 & 129 & 103 & 136 & 108 \\
\hline $9-1$ & 139 & 110 & 147 & 115 & 142 & 117 \\
\hline $9-2$ & 150 & 120 & 148 & 120 & 152 & 111 \\
\hline $10-1$ & 153 & 122 & 160 & 113 & 150 & 120 \\
\hline $10-2$ & 139 & 112 & 143 & 114 & 144 & 95 \\
\hline Average & 148 & 114 & 145 & 113 & 144 & 110 \\
\hline Max. & 169 & 133 & 162 & 130 & 158 & 125 \\
\hline Min. & 130 & 98 & 123 & 99 & 129 & 94 \\
\hline Level difference & & 35 & & 31 & & 31 \\
\hline Group distance & & 5 & & 4.4 & & 4.4 \\
\hline
\end{tabular}

Table 3. Data of differences between single yarn strength and dynamic strength $(\Delta=$ single yarn strength - dynamic strength)

\begin{tabular}{|c|c|c|c|c|c|c|c|c|c|c|}
\hline Yarn No. & 1 & 2 & 3 & 4 & 5 & 6 & 7 & 8 & 9 & 10 \\
\hline Single yarn strength & 222 & 217.5 & 230.9 & 224.8 & 219 & 216.1 & 216.1 & 223.5 & 213.1 & 219 \\
\hline Dynamic strength & 116 & 106 & 123.5 & 118.5 & 107 & 106 & 116 & 110.5 & 115 & 117 \\
\hline$\Delta$ & 106 & 111.5 & 107.4 & 106.3 & 112 & 110.1 & 110.1 & 113 & 98.1 & 102 \\
\hline Twist & 97.6 & 95.8 & 94.9 & 94.3 & 95.2 & 98.6 & 96.6 & 99.9 & 99.2 & 97.3 \\
\hline
\end{tabular}


Table 4. Experiment data between upland cotton and long-staple cotton

\begin{tabular}{|c|c|c|c|c|c|c|c|}
\hline Fiber type & $\begin{array}{c}\text { Length of } \\
\text { fiber (mm) }\end{array}$ & $\begin{array}{c}\text { Fineness } \\
\text { (tex) }\end{array}$ & $\begin{array}{c}\text { Twist } \\
\text { (twist/10cm) }\end{array}$ & $\begin{array}{c}\text { Breaking } \\
\text { strength (cN) }\end{array}$ & $\begin{array}{c}\text { Breaking } \\
\text { strength CV } \\
(\%)\end{array}$ & $\begin{array}{c}\text { Strength } \\
(\mathrm{cN} / \text { tex })\end{array}$ & $\begin{array}{c}\text { Dynamic } \\
\text { strength (cN) }\end{array}$ \\
\hline $\begin{array}{c}\text { upland } \\
\text { cotton }\end{array}$ & 29 & 20.3 & 91.4 & 205.1 & 10.6 & 10.1 & 65 \\
\hline $\begin{array}{c}\text { long-staple } \\
\text { cotton }\end{array}$ & 37 & 21.2 & 87.1 & 385.8 & 13.6 & 17.4 & 140 \\
\hline
\end{tabular}

Table 5. Experiment data of $32^{\mathrm{S}}$ yarn and $40^{\mathrm{S}}$ yarn

\begin{tabular}{|c|c|c|c|c|c|c|c|}
\hline Yarn type & $\begin{array}{c}\text { Fineness } \\
(\text { tex })\end{array}$ & $\begin{array}{c}\text { Twist } \\
(10 \mathrm{~cm})\end{array}$ & $\begin{array}{c}\text { Breaking } \\
\text { strength }(\mathrm{cN})\end{array}$ & $\begin{array}{c}\text { Breaking } \\
\text { strength CV } \\
(\%)\end{array}$ & $\begin{array}{c}\text { Strength } \\
(\mathrm{cN} / \text { tex })\end{array}$ & $\begin{array}{c}\text { Breaking } \\
\text { tension }(\mathrm{cN})\end{array}$ & $\begin{array}{c}\text { Dynamic } \\
\text { strength }(\mathrm{cN})\end{array}$ \\
\hline Pure cotton $40^{\mathrm{S}}$ & 14.4 & 97.3 & 167.7 & 16.15 & 11.6 & 128 & 100 \\
\hline Pure cotton $32^{\mathrm{S}}$ & 18.2 & 82.8 & 199.4 & 13.29 & 11 & 146 & 95 \\
\hline
\end{tabular}

Table 6. Experiment data of $32^{\mathrm{S}}$ pure yarn and $32^{\mathrm{S}}$ terylene/cotton mixed spinning

\begin{tabular}{|c|c|c|c|c|c|c|c|}
\hline Yarn type & $\begin{array}{c}\text { Fineness } \\
(\text { tex })\end{array}$ & $\begin{array}{c}\text { Twist } \\
(10 \mathrm{~cm})\end{array}$ & $\begin{array}{c}\text { Breaking } \\
\text { strength } \\
(\mathrm{cN})\end{array}$ & $\begin{array}{c}\text { Breaking } \\
\text { strength CV } \\
(\%)\end{array}$ & $\begin{array}{c}\text { Strength } \\
(\mathrm{cN} / \text { tex })\end{array}$ & $\begin{array}{c}\text { Breaking } \\
\text { tension }(\mathrm{cN})\end{array}$ & $\begin{array}{c}\text { Dynamic } \\
\text { strength } \\
(\mathrm{cN})\end{array}$ \\
\hline Pure cotton $40^{\mathrm{S}}$ & 18.2 & 82.8 & 199.4 & 13.29 & 11 & 146 & 95 \\
\hline Terylene/cotton $32^{\mathrm{S}}$ & 18.3 & 70.2 & 351.1 & 11.5 & 19.2 & 277.5 & 198.0 \\
\hline
\end{tabular}

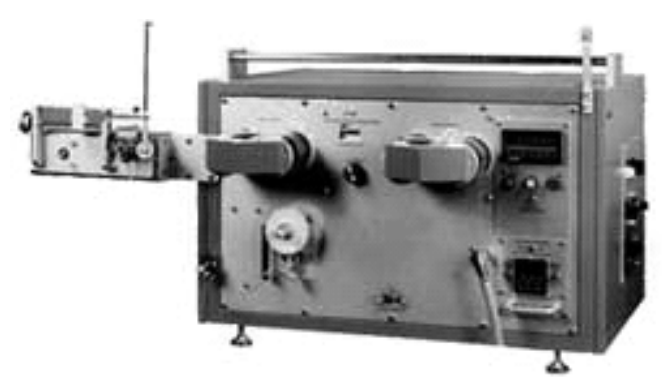

Figure 1. CTT Yarn Property Testing Instrument

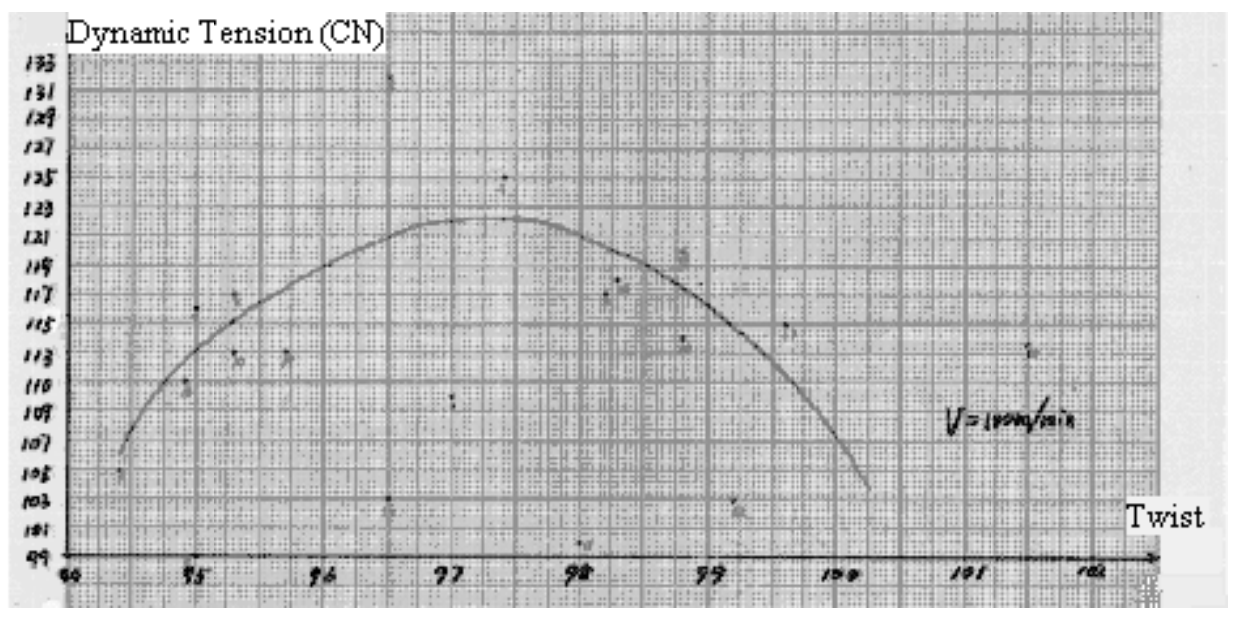

Figure 2. Twist-Dynamic Tension Curve (V=100m/min) 


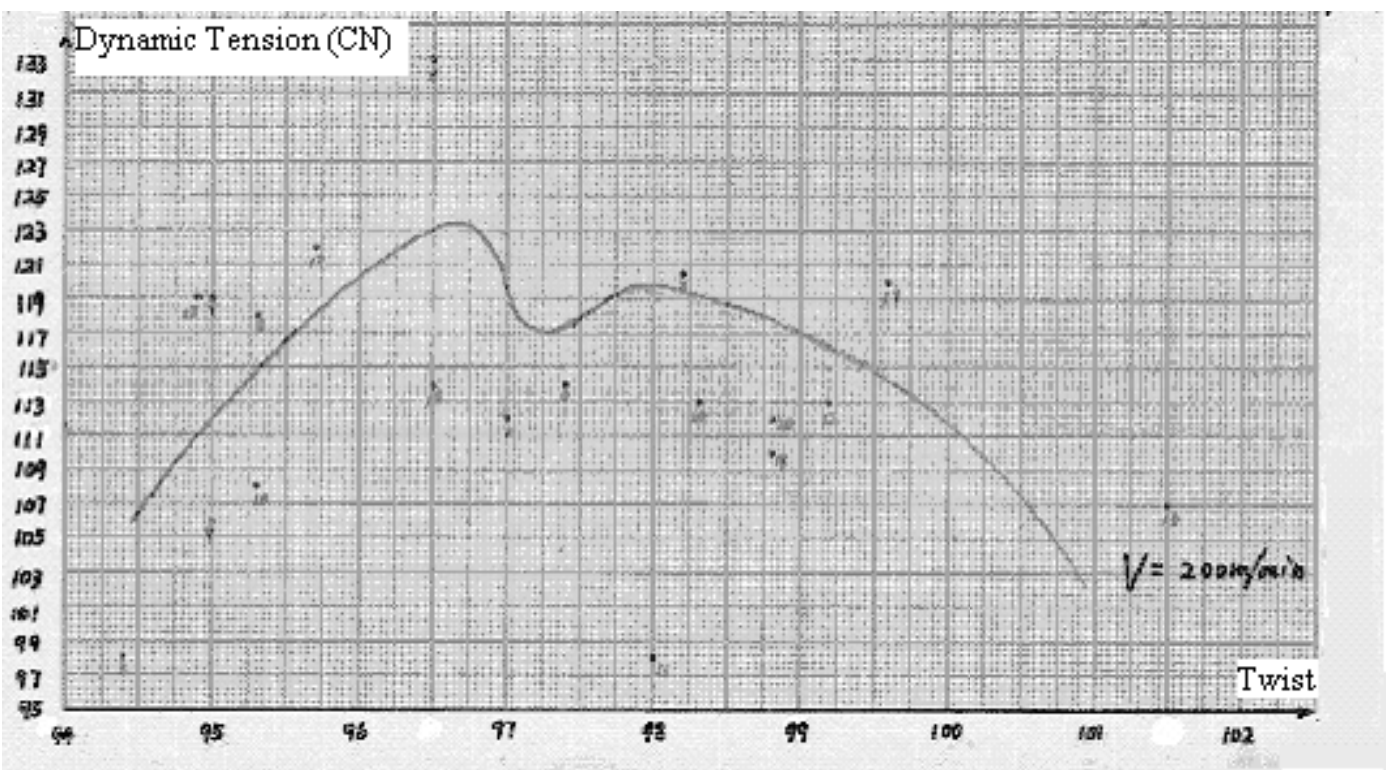

Figure 3. Twist-Dynamic Tension Curve (V=200 $/ \mathrm{min})$

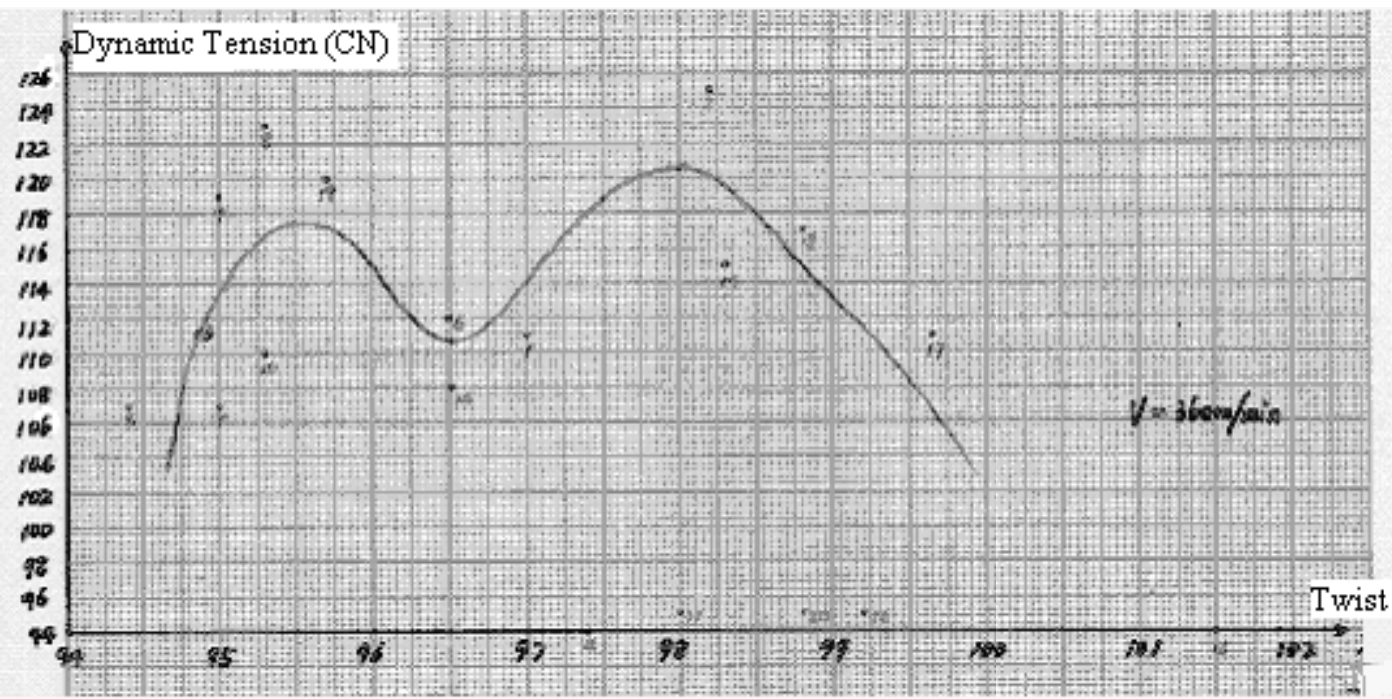

Figure 4. Twist-Dynamic Tension Curve (V=360 $/ \mathrm{min})$

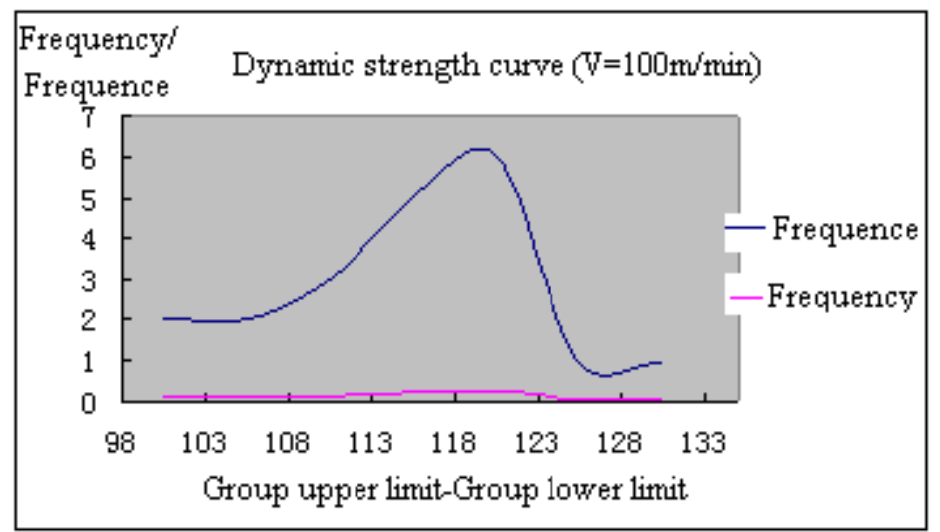

Figure 5. Dynamic Strength Curve $(\mathrm{V}=100 \mathrm{~m} / \mathrm{min})$ 


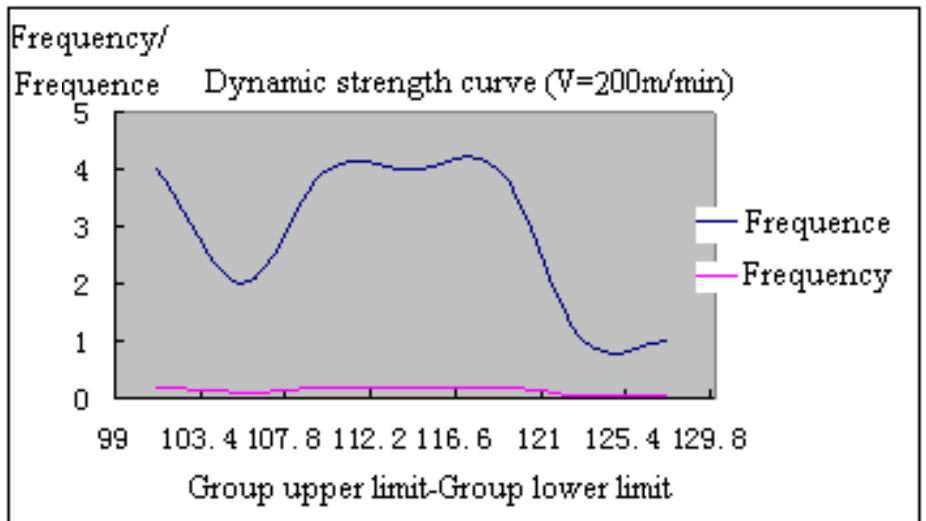

Figure 6. Dynamic Strength Curve (V=200m/min)

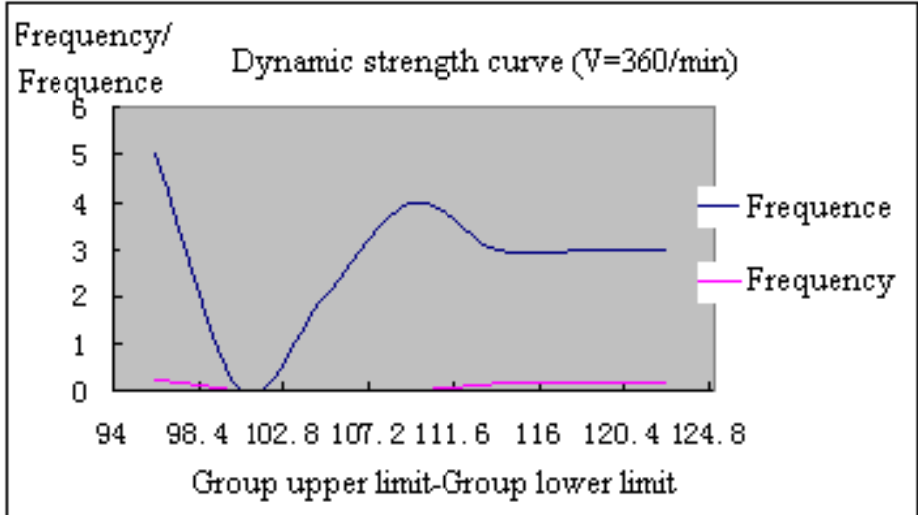

Figure 7. Dynamic Strength Curve (V=360m/min)

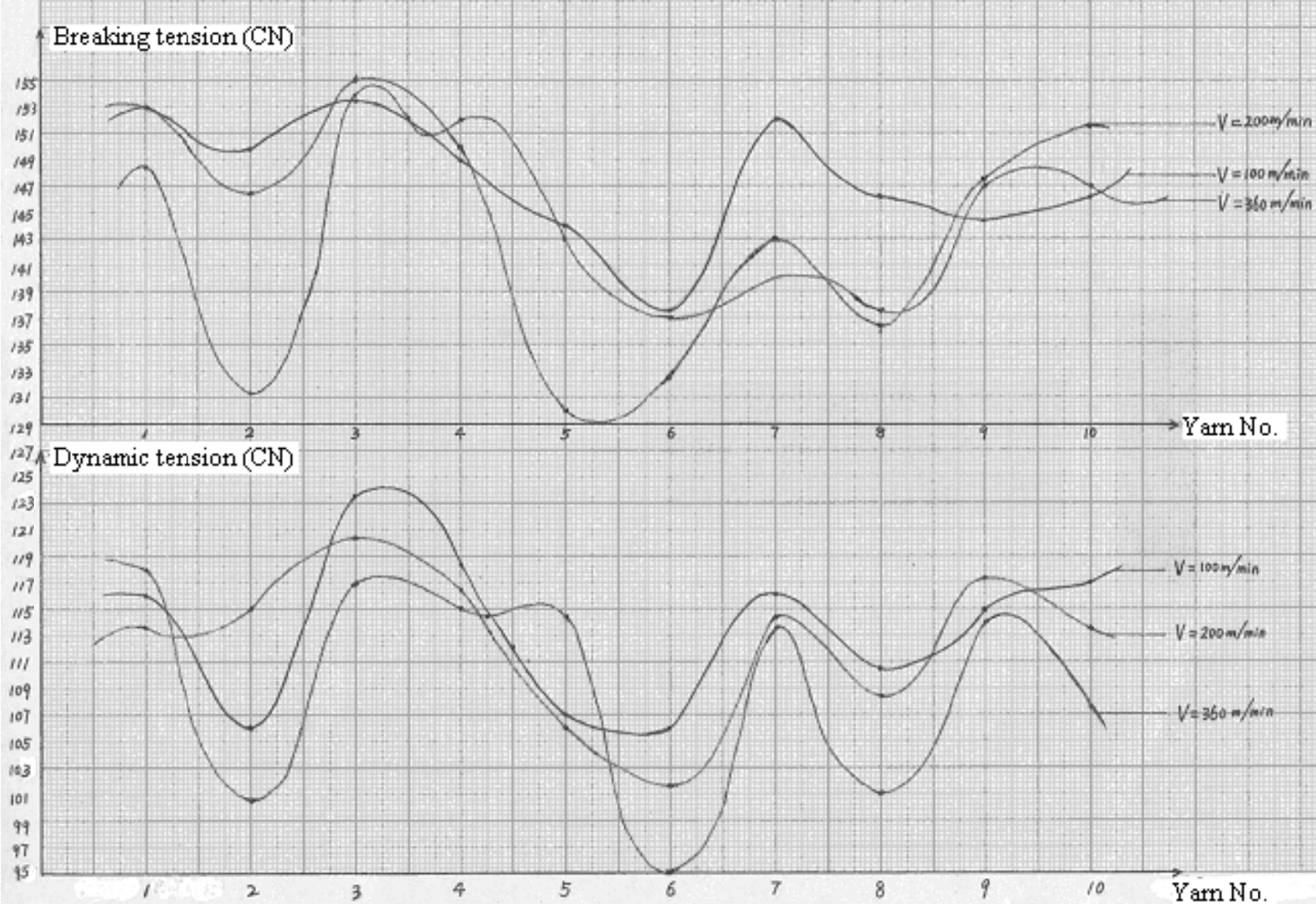

Figure 8. Breaking Tension Curve and Dynamic Tension Curve under Different Velocities 